\title{
New Approach to the Significant Reduction of Green House Gases (GHG) in Pork and Poultry Production
}

\author{
Dr Alexander Selimian ${ }^{1}$, Dr Gagik Tamanian ${ }^{2}$ \\ ${ }^{1}$ (KROOP Ltd, Armenia) \\ ${ }^{2}$ (Armacare Ltd, United Kingdom)
}

\begin{abstract}
The article describes an innovative approach to the reduction of GHG into the atmosphere by using acidolactic feed additive Vavigram-Fortissimo in animal rations. This feed additive regulates the digestion system, enabling it to reduce the intermediate organic compounds in manure. This feed additive also enables the waterless utilization of the manure into perfect quality bio humus. Experimental data of the usage of the Vavigram-Fortissimo in pig and chicken rations shows the reduction of GHG into the atmosphere by at least $20 \%$. The article also suggests an innovative new farming method that will not only result in GHG reduction but also has the potential to eliminate hunger in Third World countries.
\end{abstract}

Keywords - additive, acidolactic, bio humus, feed, manure, ration, utilization, waterless

\section{Introduction}

The article describes the impact of the innovative feed additive Vavigram-Fortissimo upon the digestive system of pigs and chickens. This impact allows the authors to introduce an innovative way of the waterless manure utilization enabling farmers to obtain perfect quality bio humus. The bio humus is then used as a perfect soil improver enabling farmers to grow certain types of oily plants to obtain their own carbon neutral bio diesel for all the energy needs of the farm. It is necessary to stress that the innovative farming method, which will be described in this article, is completely waste free and the reduction of the emission of the GHG into the atmosphere is obtained at around the $20 \%$ mark. There is also a very important aspect of the suggested innovative farming method - the farm is possible to organize as a green farming module (GFM), which can easily be implemented in remote villages and high altitude places as well as in the Third World countries in an attempt to eliminate hunger problems there.

It is well known that GHG emissions from the farming industry are much greater than, for example, from the motor vehicle usage. Thus it is imperative to try to lower the emission of GHG in the farming industry and to reduce the carbon footprint generated by human activity. The other serious task is to try to reduce hunger in the Third World countries. In this article the authors aim to show that advances in microbiology and biotechnology have the capability to also be successful in this area. Our solution is organic and could be used without a large financial investment.

\section{ACIDOLACTIC PRODUCTS - Vavigram, -Forte, -Fortissimo}

Dr Alexander Selimian has created a new biologically active food supplement, which is called Vavigram in the West and Choratan in his native country Armenia. This food supplement is very similar by its actions to a well known in the world "Narine" (only significantly more effective and powerful), which was recommended by the World Health Organization to be used widely everywhere to save newborn babies who are born with a lack of good bacteria in their guts and sadly cannot digest their mother's milk properly and die in a matter of hours.

Vavigram is a yogurt that dramatically improves digestion, boosts the immune system and lowers cholesterol and glucose levels. Vavigram is certified in several countries including Armenia, Russia and Ukraine. It is sold in pharmacies and shops and people report of a very strong life changing impact on their health and wellbeing when the Vavigram yogurt is included into their ration. The testimonials and the main impact of the usage of Vavigram upon the health can be found at www.armacarevavigram.co.uk. Here we stress that the full picture of the very positive advantages of Vavigram upon the health is much wider and most impressive.

Dr A Selimian has created two derivative products as well. First of which is called Vavigram-Forte and the second is called Vavigram-Fortissimo.

Vavigram-Forte is used to ferment the bread dough in natural way with no chemicals in roughly the same time frame as the modern bread baking industry does but with the usage of highly health damaging chemicals.

Vavigram-Fortissimo is used as a feed additive for pigs and chickens. 


\section{OUR APPROACH}

Most medium to large pig enterprises have a system of manure removal; in fact such a system must play an essential role in the farm as it supports the well-being of animals through high quality hygienic parameters and the healthy living conditions of pigs.

The world's biggest farm complexes usually use two main types of manure removal systems.

The first is called hydro flush, when the manure is removed by streams of water. The negative side of this method is high humidity levels, which may support the spread of diseases. The large quantities of water used in this method are then returned back for repeated use, which is expensive and not risk-free.

In the second method, the animals are kept on a metallic lattice and the manure drops through it. Afterwards it is again removed by large amounts of water. The main negative aspects are draughts, high water usage, high percentage of damaged hoofs and constant heavy odor.

Here we will describe the ways we suggest to keep pigs from the age of three months till the age of six months. We call it a cycle. We keep pigs on a layer of milled hay about $2 \mathrm{~cm}$ high at the beginning of the cycle. It is convenient for the animals, there are no draughts and no water is used to remove the manure, thus the humidity is kept at the normal level. Every day or when necessary the layer of hay is renovated by the workers covering the wet spots with the manure by about $2 \mathrm{~cm}$ of hay. The manure underneath the hay layer is anaerobically composted with no additional odor. At the end of the keeping cycle, about three months later, the hay layer reaches about $10-12 \mathrm{~cm}$ in height and is completely removed and taken to the utilization yard where the red Californian worms utilize it into perfect bio humus. However to make such a method of utilization of manure possible the pigs are to be fed with Vavigram-Fortissimo. Why? The manure is full of intermediate organic substances that make unfavorable conditions for the red worms to survive in it and thus make it impossible to be utilized into bio humus.

If a farmer decides to take the used hay layer into the fields it would be composted for the duration of 8-10 months with huge amounts of GHG (mainly ammonia and methane) emitted into the atmosphere. Our method of direct immediate utilization of the hay layer, without composting, by the red Californian worms is only possible when animals are fed with Vavigram-Fortissimo. The reason is that Vavigram-Fortissimo helps animals to digest the feed to a higher degree, leaving the manure with less organic intermediate substances.

Below we describe the experimental investigation upon which our method of utilization of pig manure is based.

\section{THE METHOD OF THE EXPERIMENT}

1. The experimental group of 57 pigs ( 12 males and 45 females) was chosen. Their medium weight was about $27 \mathrm{~kg}$.

2. The concrete floor of a farm building was covered by $2 \mathrm{~cm}$ of milled hay. Every day the workers were locally covering the wet spots on the layer by the additional layer of milled hay. By the end of the third month the hay layer was about $10-12 \mathrm{~cm}$ in height.

3. Before the start of the experiment the test on raw nitrogen was taken from the manure of the experimental group.

4. The same tests were carried out on the eighth, sixteenth, twenty-first and thirty-second days of the experiment, during which the animals were fed with Vavigram-Fortissimo.

5. All antibiotics and genetically modified feed components were taken off the pigs ration, thus enabling us to obtain completely organic pork.

Each probe of the manure was offered to the red Californian worms to survive in it and utilize it into bio humus. The results of all tests are presented in the table in the next section.

\section{THE ANALYSIS OF THE EXPERIMENT}

As can be seen from the table below:

1. The color of the manure has changed into black and is odorless.

2. A significant reduction of methane, ammonia and hydrogen sulfide has taken place.

3. On the $16^{\text {th }}$ day we see an increase of nitrogen in the dried manure by $15-18 \%$. This fact shows that the reduction of unstable nitrogen compounds in the manure has taken place. (The nitrogen is combined and thus the manure has no unstable nitrogen compounds and thus becomes odorless.)

4. The red Californian worms start breeding and utilizing the manure from the $16^{\text {th }}$ day after the start of the experiment.

5. 
The results of all tests are presented in the following table:

\begin{tabular}{|c|c|c|c|c|c|c|}
\hline $\begin{array}{c}\text { Days } \\
\text { during } \\
\text { which the } \\
\begin{array}{c}\text { Vavigram - } \\
\text { Fortissimo } \\
\text { was fed }\end{array}\end{array}$ & $\begin{array}{c}\text { Colour of } \\
\text { the manure }\end{array}$ & PH & $\begin{array}{c}\text { Dried } \\
\text { remnant in } \\
\%\end{array}$ & $\begin{array}{c}\text { Nitrogen } \\
\text { ammonia in } \\
\%\end{array}$ & $\begin{array}{c}\text { Nitrogen in } \\
\text { dried mass } \\
\text { in } \%\end{array}$ & $\begin{array}{c}\text { Red worms } \\
\text { survival }\end{array}$ \\
\hline 0 & $\begin{array}{c}\text { Light } \\
\text { brown }\end{array}$ & 7.6 & 22.83 & 0.196 & 2.75 & $\begin{array}{c}\text { Died in 5 } \\
\text { hrs }\end{array}$ \\
\hline 8 & Brown & 7.6 & 24.88 & 0.210 & 2.52 & $\begin{array}{c}\text { Died in 3 } \\
\text { hrs }\end{array}$ \\
\hline 16 & Dark brown & 7.3 & 34.0 & 0.170 & 2.3 & $\begin{array}{c}\text { Utilized the } \\
\text { manure }\end{array}$ \\
\hline 24 & Black & 7.1 & 34.2 & 0.169 & 2.28 & $\begin{array}{c}\text { Utilized the } \\
\text { manure }\end{array}$ \\
\hline 32 & Black & 7.1 & 34.1 & 0.170 & 2.29 & $\begin{array}{c}\text { Worms } \\
\text { were } \\
\text { breeding in } \\
\text { it }\end{array}$ \\
\hline
\end{tabular}

Fig 1. Table of Results

\section{CONCLUSIONS FROM THE EXPERIMENT}

The experimental data shows that the way of regulating the guts' fermentation in pigs is found.

During the first 16 days of the usage of Vavigram-Fortissimo as feed additive, the reorganization of the guts' micro flora is taking place and after that we see the stabilization of the digestion process.

A significant reduction of nitrogen compounds in the guts during the digestion process is evident. This explains the increase of the amount of combined nitrogen in the manure and the significant reduction of the specific heavy and unpleasant odor of the manure.

The reduction by $15-20 \%$ of the emission of GHG into the atmosphere is evident (in carbon dioxide equivalent). The used hay layer straight away (without preliminary composting) is used as a nourishing field for Californian red worms to breed and to turn it into bio humus.

Significant reduction of water usage in the farm is evident, as water is not needed to flush the manure. That helps to keep pigs in a much healthier microclimate.

It also enables us to use this method in places with a shortage of water. This method is not only the cheapest but it also helps to fertilize the soil in the fields. Red Californian worms breed quickly in the manure and the excess of them could be used as a perfect protein feed for pigs and chickens.

The weight gains are increased by $12-15 \%$ compared with the pigs that do not receive Vavigram-Fortissimo as a feed additive. This happens due to the increased digestion of the feed.

The reduction of the intercellular water in the meat is taking place as Vavigram-Fortissimo helps to cleanse the pig's body from the toxins.

\section{VAVIGRAM-FORTISSIMO}

Vavigram-Fortissimo is an acidolactic product with high content of acidophilic bacteria (1.2-1.5 billion per gram). It also has 16 amino acids, 8 of which are irreplaceable.

It has been obtained by using microbiological technological processes created by Dr Alexander Selimian.

Vavigram-Fortissimo is used as a feed additive for pigs and it does make sense as all mammals begin their life cycle by the usage of their mother's milk. Thus the usage of the acidolactic feed additive is completely natural.

We should stress here that the feed industry constantly attempts to increase the effectiveness of the pig's feed and at the present moment the pig's digestive system is very close to the limit of its ability to process the feed. That is why a significant amount of the feed travels through the stomach to the intestines with the formation of a huge amount of intermediate nitrogen and hydrogen sulfide compounds in the manure. In the air, in contact with the oxygen, they are quickly oxidized and decomposed into ammonia, methane and hydrogen sulfide.

In such processes almost all energy of the animal is used for the digestive process and thus the immune system of the animal becomes weaker and weaker.

Also the formation of a huge amount of toxins during the metabolic process increases the intercellular water in meat, which is usually taken as additional weight gain, which is obviously wrong. 
In the process of obtaining the Vavigram-Fortissimo we use the traditional technological processes of obtaining acidolactic products with the usage of the starters obtained by modern microbiologically advanced methods with constant microbiological control, to ensure for the best quality of the product. Thus Vavigram-Fortissimo is a completely natural feed additive with no preservatives and other artificial substances.

\section{GREEN FARMING MODULE (GFM)}

Based on the experiments described above, we have created a new farming method which would not only reduce the GHG emission by $18-20 \%$ but which also has the potential to assist in tackling the Third World hunger problems.

We invite readers to imagine a farm with a small lab where the acidolactic products are manufacturedVavigram, Vavigram-Forte and Vavigram-Fortissimo. Such a complex technological line has no waste, which is very important to point out. The importance of it will become more obvious if we state that it enables the whole GFM to function as a waste free unit.

Vavigram is used by humans to improve their digestive and immune systems. Benefits of taking it include losing and maintaining weight, lowering cholesterol and glucose levels, getting more energy, normalizing blood pressure and improving skin conditions such as psoriasis.

Vavigram-Forte is used to bake breads of perfect quality with no chemicals and toxins in it.

Vavigram-Fortissimo is used as a feed additive for pigs, chickens and can be used for other farm animals as well.

Pigs are brought up in a completely organic way with no use of antibiotics and other genetically modified products. Thus we produce pork, which is of the top market quality and is $100 \%$ organic.

The manure of the pigs is utilized by red Californian worms, turning it into high quality bio humus.

The bio humus is taken to the fields to fertilize the soil and to enable the villagers to grow the necessary quantity of oily plants such as jatropha for instance (in warm and hot climates). The oily plants are then taken to the other unit within the GFM where the oil is extracted and the bio fuel is obtained.

The bio fuel is used as an energy source for all the needs of GFM.

Please note that in many developed countries it is possible to envisage the additional usage of the bio diesel in obtaining electricity and to feed the grid with the excess of it.

In the above-mentioned cycle of technological processes we obtain many intermediate products such as glycerin, pure protein etc, which are also used in farming.

\section{VAVIGRAM-FORTISSIMO FOR BROILERS}

It is necessary to mention here that when broilers were fed with Vavigram-Fortissimo we were able to obtain a significant weight gain and a significant reduction in mortality rate as well as the complete elimination of the usage of antibiotics and other genetically modified products.

The significant fact is that the chicken manure also becomes odorless and it is also utilized according to the above-described method used for pig's manure (with the aid of Vavigram-Fortissimo).

The organic chicken meat is of perfect top market quality and is tender and juicy, exactly the same way as pork.

\section{GFM FOR REMOTE PLACES}

Now we invite readers to imagine a remote village with hardly any energy sources to function, struggling to survive. Imagine that we were able to provide 100 cows to all inhabitants of such a village to take care of. In return they would need to supply the GFM of their village 10L of milk daily to enable the production of the acidolactic products and thus to enable the GFM to start the full cycle of the production lines including the pig and chicken farm.

Here is the diagrammatical representation of the whole cycle: 


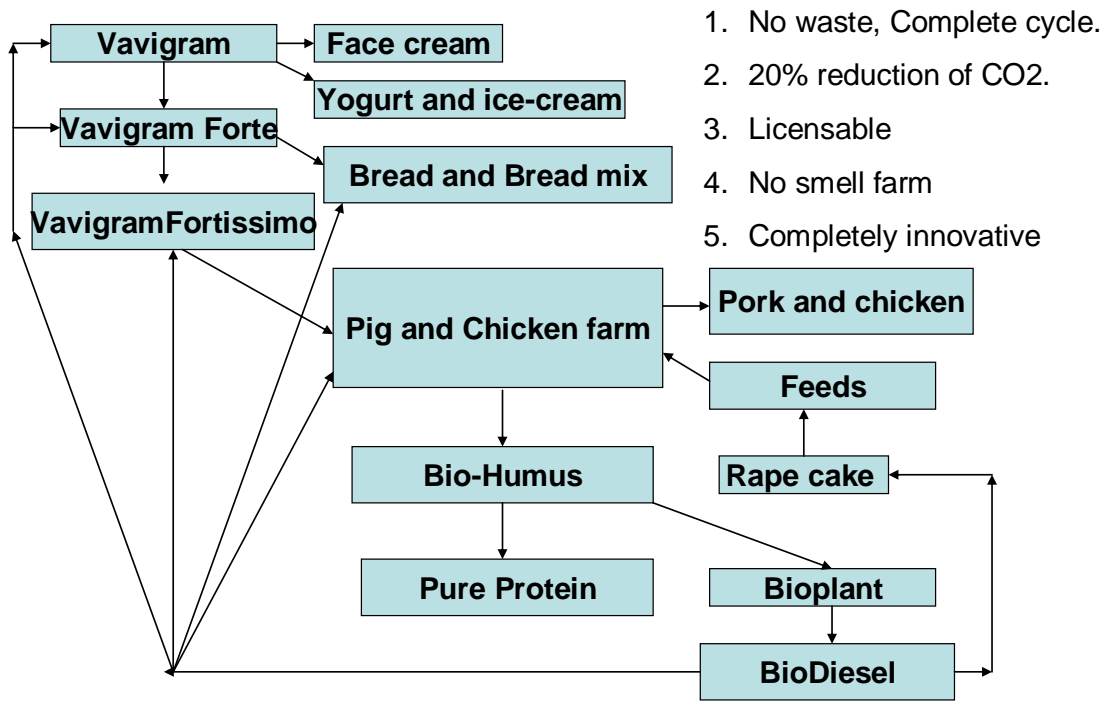

Fig 2. Green Farming Module

GFM would employ about 30 villagers to function. The villagers would benefit from the perfect quality of pork and chicken meat available for them at a reasonable price. Overall the GFM is capable of producing about 15 products for the villagers thus helping them to increase the quality of their lives and to tackle the problem of hunger as well as the problem of energy supply.

\section{CONCLUSION}

Our experimental data and research shows that by using the acidolactic feed additive VavigramFortissimo it is possible to change and regulate the digestive processes in pigs and chickens and thus to cut the process of formation of intermediate organic compounds, which in turn lowers the emission of GHG into the atmosphere.

We have suggested a new method of utilization of pig and chicken fresh manure (without composting) and thus the usage of new farming method in the form of Green Farming Module with a progressive way of successfully tackling the problem of energy supply and the elimination of hunger in the Third World countries and in remote villages everywhere else.

We stress that this new approach is particularly beneficial for small and remote farms as it doesn't need huge financial investments and is competitive in the production of organic meat products. 